\title{
Virulence plasmid pJM1 prevents the conjugal entry of plasmid DNA into the marine fish pathogen Vibrio anguillarum 775
}

\author{
John T. Singer, ${ }^{1 *}$ Wonkyu Choe,${ }^{1} \dagger$ KaTherine A. SchmidT ${ }^{1}$ and Ronald A. MaKula ${ }^{2}$ \\ ${ }^{1}$ Department of Biochemistry, Microbiology and Molecular Biology, University of Maine, Orono, Maine 04469, USA \\ ${ }^{2}$ Department of Biochemistry, University of Georgia, Athens, Georgia 30602, USA
}

(Received 13 March 1992; revised 1 July 1992; accepted 3 August 1992)

\begin{abstract}
Studies involving the introduction of cloned homologous genes into Vibrio anguillarum revealed that several plasmids could not be conjugally introduced into $V$. anguillarum 775 (pJM1), but were transmissible to the pJM1cured derivative H775-3. Recombinant pBR322 plasmids containing $V$. anguillarum genomic DNA inserts were mobilized from Escherichia coli donors, using pRK2013, into $V$. anguillarum H775-3 recipients at frequencies of $10^{-6}$ to $10^{-5}$ per recipient. When identical matings were performed with $V$. anguillarum 775 (pJM1) recipients, the infrequent exconjugants recovered carried the pBR322-based plasmid but had lost the large virulence plasmid pJM1. Similar studies were carried out with plasmid RP4 and with recombinant derivatives of the closely related broad-host-range plasmid pRK290. While RP4 was transmissible from $E$. coli to $V$. anguillarum $\mathrm{H} 775-3$ at frequencies of $6.7 \times 10^{-2}$ per recipient, transmission to $V$. anguillarum 775 (pJM1) recipients occurred at frequencies of only $2.5 \times 10^{-7}$. When pRK290 contained $V$. anguillarum DNA inserts, the only exconjugants recovered had lost pJM1, or contained pJM1 and a deletion derivative of the recombinant pRK290 plasmid where all of the DNA insert had been deleted. The use of $\mathrm{Dam}^{-}, \mathrm{Dcm}^{-}$, or $E c o K-$ methylation-deficient $E$. coli donor strains failed to result in appreciable numbers of $V$. anguillarum 775(pJM1) exconjugants that contained the desired transferred plasmids. Following UV mutagenesis, a derivative of $V$. anguillarum 775(pJM1) was isolated that would accept conjugally transferred plasmid DNAs at frequencies similar to those observed when using $V$. anguillarum H775-3 recipients. These data suggest that virulence plasmid pJM1 mediates a restriction system that prevents conjugal transmission of plasmid DNA from $E$. coli donors into $V$. anguillarum 775(pJM1). This putative restriction system appears not to be directed towards Dam-, Dcm-, or EcoK-methylated DNA, and appears not to involve a Type II restriction endonuclease.
\end{abstract}

\section{Introduction}

Vibriosis, caused by the ubiquitous marine bacterium Vibrio anguillarum, results in a rapidly progressive haemorrhagic septicaemia that can account for high mortalities among marine animals, and especially among salmonids under conditions of high-density aquaculture. In Japan, where accurate data are available, losses of farmed finfish due to vibriosis alone exceed 20 million US dollars annually (Austin \& Austin, 1987).

$V$. anguillarum serotype $\mathrm{O} 1$ is the serotype that predominates among cultured diseased fish, and especially among salmon and trout (Bolinches et al., 1990; Larsen \& Olsen, 1991; Larsen et al., 1988; Myhr et al.,

* Author for correspondence. Tel. (207) 581-2808; fax (207) 5812801.

† Present address: M. D. Anderson Cancer Research Center, PO Box 389, Smithville, Texas 78957, USA.
1991; Toranzo \& Barja, 1990; Toranzo et al., 1987). Virulence of this serotype of $V$. anguillarum is nearly always due to the presence of $65-70 \mathrm{~kb}$ pJMl-like virulence plasmids that encode a high-affinity ironuptake system (Crosa, 1989; Crosa et al., 1977, 1985; Olsen \& Larsen, 1990; Tolmasky et al., 1988; Wiik et al., 1989). Over the past seven years, 267 serotype $O 1$ isolates from diseased fish around the world have been described; 260 carried a virulence plasmid that was similar or identical to $\mathrm{pJM} 1$, and only nine of these isolates carried additional plasmids (Bolinches et al., 1990; Conchas et al., 1991 ; Larsen \& Olsen, 1991 ; Lemos et al., 1988; Myhr et al., 1991; Tolmasky et al., 1988; Wiik et al., 1989). Thus, it appears that in the case of fishpathogenic serotype $O 1$ strains of $V$. anguillarum, pJM1 may be a serospecific plasmid analogous to the 36 MDa plasmid associated with virulent Salmonella enteritidis isolates (Threlfall et al., 1989). 
The observation that similar or identical virulence plasmids exist in biochemically, geographically and genetically distinct backgrounds of $V$. anguillarum throughout the world raises intriguing questions concerning the dissemination of virulence determinants among bacteria in the marine environment, and between $V$. anguillarum strains in particular. While transposition has been suggested as a possible explanation for the dissemination of the $25 \mathrm{~kb}$ iron-uptake virulence region of pJM1 DNA (Crosa et al., 1985), this mechanism cannot account for the high degrees of similarity observed among pJM1-like plasmids, often encompassing 60-65 kb of DNA. Thus far, conjugal transmission of pJM1 has not been reported, nor has it been possible to transduce pJM1 with vibriophage $\phi A s 3$, or to demonstrate transposition or transformation in the laboratory (J. T. Singer, unpublished observations).

To examine more thoroughly the transmissibility of pJM1 virulence determinants, we attempted first to tag virulence DNA regions with an easily selectable $1.2 \mathrm{~kb}$ kanamycin-resistance determinant via marker exchange, mediated by homologous recombination (Singer et al., $1991 a, b)$. However, all initial attempts to introduce plasmid DNA into $V$. anguillarum 775 (pJM1) by conjugation failed. We present evidence here for the presence of a pJM1-mediated restriction system as an explanation for the initial difficulties in introducing plasmid DNA into $V$. anguillarum 775(pJM1). This explanation might also serve to reconcile the observation that pJM1-like plasmids rarely occur in nature in the presence of other plasmids.

\section{Methods}

Bacterial strains. Rifampin-resistant $V$. anguillarum 775R1(pJM1) and the pJMl-cured strain $V$. anguillarum H775-3 were described previously (Singer $e t$ al., 1991 $a, b$ ). Escherichia coli strains used in this study and their relevant characteristics included $\mathrm{HB} 101\left[\mathrm{r}_{\mathrm{B}}^{-}, \mathrm{m}_{\overline{\mathrm{B}}}^{-}, \mathrm{Mar}^{-}\right.$, McrB $\left.^{-}, E c o K^{-}\right]$(Raleigh \& Wilson, 1986), HB101(pRK2013) and HB101(pRK290) (Ditta et al., 1980), J53(RP4) (Thomas, 1981), GM2929 [dam-13 ::Tn9 dcm-6 hsdR2 mcrA mcrBI] (from Michael G. Marinus, Department of Pharmacology, University of Massachusetts Medical School, Worcester, Massachusetts 01655, USA), and ER1647 [mcrA1272::Tn10, $\Delta(m c r C B-h s d S M R-m r r) 2-T n 10]$ (from Elisabeth A. Raleigh, New England Biolabs, Beverly, Massachusetts 01915, USA).

Plasmid-encoded phenotypes and incompatibility groups. Plasmid pRK2013 (Inc la) encodes kanamycin resistance and is a restrictedhost-range, PolA-dependent helper plasmid that carries plasmid RK2 transfer genes cloned into plasmid ColEl (Figurski \& Helinski, 1979). Plasmid pRK290 (Inc P) encodes tetracycline resistance and is a $20 \mathrm{~kb}$ mobilizable RK2-based broad-host-range cloning vector for use in Gram-negative organisms (Ditta et al., 1980). RP4 (Inc P) is a broadhost-range conjugative plasmid highly similar to RK2 that encodes resistance to ampicillin, tetracycline and kanamycin (Thomas, 1981). Plasmid pBR322 (Inc Ia) is a restricted-host-range pMBl-based vector encoding ampicillin and tetracycline resistance (Balbas et al., 1988). Virulence plasmid pJMl carries no known antibiotic resistance determinants, but codes for the production of the siderophore anguibactin and its cognate ferric-anguibactin transport components (Crosa, 1989). pJM1 has been described only from $V$. anguillarum isolates and has not been assigned an incompatibility group. However, Crosa et al. (1977) demonstrated that pJM1 shares little or no ( $\leq 1 \%)$ sequence homology with plasmids from incompatibility groups FI, FII, $\mathrm{P}, \mathrm{X}, \mathrm{N}, \mathrm{W}, \mathrm{I}$ and $\mathrm{O}$. When transformed into $E$. coli hosts, selectable pJM1-kan plasmids (Singer $e t$ al., $1991 b$ ) are compatible with plasmids pBR322, RP4, and with their derivatives (J. T. Singer, unpublished observations).

Media and growth conditions. $V$. anguillarum strains were grown in $\mathrm{L}$ broth containing $2 \%(\mathrm{w} / \mathrm{v}) \mathrm{NaCl}$ at $26^{\circ} \mathrm{C}$, or on $\mathrm{L}$ agar- $2 \% \mathrm{NaCl}$ plates containing $1.6 \%(w / v)$ agar. $E$. coli strains were grown in $\mathrm{L}$ broth or on $\mathrm{L}$ agar plates at $37^{\circ} \mathrm{C}$. Where required, antibiotics were used at the following final concentrations: ampicillin, 100 or $400 \mu \mathrm{g} \mathrm{ml}^{-1}$; kanamycin, $50 \mu \mathrm{g} \mathrm{ml}^{-1}$; tetracycline, $5 \mu \mathrm{g} \mathrm{ml}^{-1}$; and rifampin, $100 \mu \mathrm{g}$ $\mathrm{ml}^{-1}$.

Molecular biological techniques. Plasmid DNA isolations, purification, digestions, ligations, transformation, and conditions for agarose gel electrophoresis were as previously described (Singer \& Earley, 1989).

Construction of $p C W 1$ and $p C W 2$. Plasmid pSE6 (Singer \& Earley, 1989) contains a $13.6 \mathrm{~kb}$ Xhol fragment of pJM1 iron-uptake DNA inserted into the compatible Sall site of pBR322, thereby destroying both $X h o I$ and $S a l l$ recognition sequences at the junctions of insert and vector DNAs. A $1.2 \mathrm{~kb}$ Sall DNA fragment encoding kanamycin resistance was purified (Lizardi et al., 1984) from plasmid pUC4-K (Vieira \& Messing, 1982) and was inserted into the unique Sall site of cloned pJMI DNA, resulting in plasmid pSE6-kanl (Singer et al., $1991 b$ ). A $10 \cdot 8 \mathrm{~kb}$ EcoRI DNA fragment containing the central portion of cloned pJM1 iron-uptake DNA along with the kan insert was purified from pSE6-kanl (Singer et al., 1991 b) and was ligated into the unique EcoRI site within plasmids pBR322 and pRK290, resulting in plasmids pCW2 (15.2 kb) and pCW1 (30.8 kb), respectively.

Conjugal matings. Triparental filter matings using the helper plasmid pRK2013 were used to mobilize pBR322 and pRK290 derivatives from E. coli donors into $V$. anguillarum recipients. Overnight $5 \mathrm{ml}$ cultures of donor and recipient cells, grown under selection, were harvested by centrifugation and suspended in $5 \mathrm{ml}$ of $\mathrm{L}$ broth or $\mathrm{L}$ broth $-2 \% \mathrm{NaCl}$ to remove traces of antibiotic. Equal volumes (1-1.5 ml) of donor and recipient cultures were mixed, and filtered through $47 \mathrm{~mm} 0.45 \mu \mathrm{m}$ membrane filters; the filters were placed on the surface of $\mathrm{L}$ agar plates containing $1.0 \%(\mathrm{w} / \mathrm{v}) \mathrm{NaCl}$ and were incubated at $26^{\circ} \mathrm{C}$ for $18 \mathrm{~h}$. Cells were then resuspended and diluted in $\mathrm{L}$ broth- $2 \% \mathrm{NaCl}$, and dilutions were plated onto $\mathrm{L}$ agar- $2 \% \mathrm{NaCl}$ plates supplemented with rifampin and additional appropriate antibiotics to select exconjugants of $V$. anguillarum. Following a $48 \mathrm{~h}$ incubation at $26^{\circ} \mathrm{C}$, exconjugants were quantified and transfer frequencies were calculated per recipient plated.

Restriction endonuclease purification. Putative restriction endonuclease activity was purified from $V$. anguillarum $775 \mathrm{R} 1$ (pJM1) and 775R1Rsut(pJM1) according to Makula \& Meagher (1980). Enzyme activity was assayed according to Makula \& Meagher (1980) or by the method of Schleif (1980).

\section{Results and Discussion}

\section{pJM1-mediated restriction}

Results presented in Table 1 show that plasmid pBR322, and pBR322-based recombinant plasmids such as 
Table 1. Conjugal transfer of restricted-host-range and broad-host-range plasmids to $V$. anguillarum

Filter matings were performed as described in the text. Plasmid transfer frequencies are the mean \pm SD for triplicate determinations. ND, None detected. Normal limit of detection was approximately $10^{-9}$ exconjugants per recipient plated.

\begin{tabular}{|c|c|c|c|}
\hline Donor & Recipient & Selection & $\begin{array}{l}\text { Exconjugants per } \\
\text { recipient plated }\end{array}$ \\
\hline $\begin{array}{c}\mathrm{HB} 101(\mathrm{pBR} 322)+ \\
\text { HB101(pRK2013) }\end{array}$ & $\begin{array}{l}\text { H775-3 } \\
\text { 775R1(pJM1) }\end{array}$ & $\begin{array}{l}\text { Rif }+A p \\
\text { Rif }+A p\end{array}$ & $\begin{array}{c}2.2 \pm \underset{N D}{0.5} \times 10^{-5} \\
\text { ND }\end{array}$ \\
\hline $\begin{array}{l}\text { HB101(pCW2) }+ \\
\text { HB101(pRK2013) }\end{array}$ & $\begin{array}{l}\text { H775-3 } \\
775 R 1 \text { (pJM1) }\end{array}$ & $\begin{array}{l}\text { Rif }+A p \\
\text { Rif }+A p\end{array}$ & $\begin{array}{c}1.6 \pm \underset{N D^{*}}{0.7} \times 10^{-6} \\
\end{array}$ \\
\hline J53(RP4) & $\begin{array}{l}\text { H775-3 } \\
775 R 1(\mathrm{pJM} 1)\end{array}$ & $\begin{array}{l}\text { Rif }+A p \\
\text { Rif }+A p\end{array}$ & $\begin{array}{l}6.7 \pm 2.7 \times 10^{-2} \\
2.5 \pm 0.6 \times 10^{-7}\end{array}$ \\
\hline $\begin{array}{c}\text { HB101(pRK290) }+ \\
\text { HB101(pRK2013) }\end{array}$ & $\begin{array}{l}\text { H775-3 } \\
775 R 1 \text { (pJM1) }\end{array}$ & $\begin{array}{l}\text { Rif }+ \text { Tc } \\
\text { Rif }+ \text { Tc }\end{array}$ & $\underset{\text { ND }}{3.8 \pm 0.7} \times 10^{-6}$ \\
\hline HB101(pRK290, pRK2013) & $\begin{array}{l}\text { H775-3 } \\
\text { 775R1(pJM1) }\end{array}$ & $\begin{array}{l}\text { Rif }+\mathrm{Tc} \\
\mathrm{Rif}+\mathrm{Tc}\end{array}$ & $\underset{\text { ND }}{3.3} \pm \frac{0.7}{0} \times 10^{-5}$ \\
\hline HB101(pCW1, pRK2013) & $\begin{array}{l}\text { H775-3 } \\
775 R 1(\mathrm{pJM})\end{array}$ & $\begin{array}{l}\text { Rif }+T c \\
\text { Rif }+T c\end{array}$ & $\begin{array}{c}1.4 \pm 0.4 \times 10^{-5} \\
\mathrm{ND} \dagger\end{array}$ \\
\hline
\end{tabular}

- Two Rifr Apr exconjugants were isolated; both contained pCW2 but were cured of pJM1.

$\dagger$ Four $\mathrm{Rif}^{\mathrm{r}} \mathrm{Tc}^{\mathrm{r}}$ clones were isolated; one carried $\mathrm{pCW} 1$ but was cured of $\mathrm{pJM} 1$, and three carried pJM1 but contained deletion derivatives of $\mathrm{pCW} 1$ in which all of the cloned $\mathrm{pJM} 1$ DNA had been deleted.

Table 2. Conjugal transfer of plasmids from methylase-deficient donors to

$$
V \text {. anguillarum }
$$

Filter matings were performed as described in the text. Plasmid transfer frequencies are the mean \pm SD for triplicate determinations. ND, None detected. Normal limit of detection was approximately $10^{-9}$ exconjugants per recipient plated.

\begin{tabular}{cllc}
\hline \hline Donor & Recipient & Selection & $\begin{array}{c}\text { Exconjugants per } \\
\text { recipient plated }\end{array}$ \\
\hline GM2929(pBR322) + & H775-3 & Rif + Ap & $1 \cdot 2 \pm 0.4 \times 10^{-6}$ \\
HB101(pRK2013) & $775 R 1(\mathrm{pJM} 1)$ & Rif + Ap & ND \\
ER1647(pBR322) + & H775-3 & Rif + Ap & $2 \cdot 2 \pm 0.4 \times 10^{-5}$ \\
HB101(pRK2013) & $775 R 1(\mathrm{pJM} 1)$ & Rif + Ap & $4.0 \pm 3.0 \times 10^{-9}$ \\
\hline \hline
\end{tabular}

pCW2, could be introduced into plasmid-free $V$. anguillarum $\mathrm{H} 775-3$, but not into $V$. anguillarum $775 \mathrm{R} 1$ carrying virulence plasmid $\mathrm{pJM} 1$. The presence of $\mathrm{pJM} 1$ also appeared to decrease conjugal transmission of broad-host-range plasmid RP4 by a factor of $>10^{5}$. Similar effects were also observed when the broad-hostrange cloning vector pRK290 was mobilized into $V$. anguillarum 775R1(pJM1) (Table 1).

The results in Table 1 suggest that virulence plasmid pJM1 mediates a restriction or exclusion system that prevents the conjugal transmission of plasmid DNA into $V$. anguillarum. This system probably involves an endonuclease/exonuclease activity, rather than surface exclusion, based upon results obtained with crosses between $E$. coli HB101(pCW1, pRK2013) and $V$. anguillarum 775R1(pJM1) (Table 1). From several of these crosses, a total of four exconjugants were eventually isolated. One contained pCW1 but was cured of pJM1.
The remaining three exconjugants contained full-length pJM1 plasmids, as determined by restriction endonuclease analysis, but contained $17-19 \mathrm{~kb}$ deletion derivatives of pCW1 $(30.8 \mathrm{~kb})$ in which all of the cloned DNA had been deleted, and in which deletions extended into vector DNA sequences to varying degrees (not shown). These results support the existence of a pJM1-encoded or pJM1-controlled enzymic activity responsible for degradation of the incoming plasmid DNAs.

\section{Use of methylase-deficient donor strains}

Since methyl-specific restriction endonucleases might be active against DNAs that display specific patterns of DNA methylation (Raleigh et al., 1991), E. coli donors that were methylation deficient were tested to determine whether plasmid transfer frequencies might be increased. The results in Table 2 show that GM2929 was 
Table 3. Conjugal transfer of plasmids to restriction-deficient $V$. anguillarum

Filter matings were performed as described in the text. Plasmid transfer frequencies are the mean \pm SD for triplicate determinations.

\begin{tabular}{llll}
\hline \hline \multicolumn{1}{c}{ Donor } & \multicolumn{1}{c}{ Recipient } & Selection & $\begin{array}{c}\text { Exconjugants per } \\
\text { recipient plated }\end{array}$ \\
\hline J53(RP4) & H775-3 & Rif + Ap & $6.7 \pm 2.7 \times 10^{-2}$ \\
& 775R1Rsut(pJM1) & Rif + Ap & $1 \cdot 1 \pm 0.3 \times 10^{-1}$ \\
HB101(pBR322) + & H775-3 & Rif + Ap & $2.1 \pm 0.4 \times 10^{-5}$ \\
HB101(pRK2013) & 775R1Rsut(pJM1) & Rif + Ap & $1 \cdot 7 \pm 0.4 \times 10^{-5}$ \\
ER1647(pBR322) + & H775-3 & Rif + Ap & $2.3 \pm 0.5 \times 10^{-5}$ \\
HB101(pRK2013) & 775R1Rsut(pJM1) & Rif + Ap & $5.0 \pm 0.4 \times 10^{-5}$ \\
HB101(pCW2) + & H775-3 & Rif + Ap & $1.8 \pm 0.4 \times 10^{-6}$ \\
HB101(pRK2013) & 775R1Rsut(pJM1) & Rif + Ap & $1 \cdot 7 \pm 0.4 \times 10^{-6}$ \\
\hline \hline
\end{tabular}

even a lower efficiency donor than HB101 when $V$. anguillarum $\mathrm{H} 775-3$ was the recipient; when $V$. anguillarum 775R1(pJM1) was the recipient, no exconjugants were detected. However, the use of ER1647 as a donor strain in matings resulted in exconjugants of both $V$. anguillarum $\mathrm{H} 775-3$ and $775 \mathrm{R} 1$ (pJM1). While exconjugants of $V$. anguillarum 775R1(pJM1) were isolated only at very low frequency, ten exconjugants that were examined carried both full-length pJM1 and pBR322 plasmids.

These results indicate that the pJM1-mediated restriction system is not targeted towards Dam-, Dcm-, or EcoK-methylated DNA. In view of their similar genotypes with respect to methylation, it is difficult to explain the observation that ER1647 acts as a low-frequency donor while HB101 does not. It is possible that the escape from restriction observed with ER 1647 donors was due to the deletion of additional sequences upstream or downstream from $h s d R M S$ that may influence methylase activities in an unknown fashion.

\section{Isolation of restriction-defective mutants of $V$. anguillarum}

Since mating frequencies using ER 1647 donors and $V$. anguillarum 775R 1 (pJM1) recipients were still too low to be generally useful in the laboratory, we attempted to isolate a restriction-defective mutant of $V$. anguillarum $775 \mathrm{R} 1$ (pJM1). Cells were grown in M9 minimal medium, supplemented as previously described (Singer \& Earley, 1989), to an $\mathrm{OD}_{600}$ of 0.5 and were chilled on ice. A $5.0 \mathrm{ml}$ culture sample was irradiated $\left(3 \mathrm{~J} \mathrm{~m}^{-2}\right)$ at $254 \mathrm{~nm}$ in the bottom of a standard glass Petri dish, in the dark with gentle shaking ( 50 r.p.m.). Surviving cells were then allowed to grow overnight in the dark and cells in the culture were used as recipients in matings with HB101(pBR322) and HB101(pRK2013).

Rare $V$. anguillarum exconjugants were selected on medium containing rifampin and ampicillin $(400 \mu \mathrm{g}$ $\mathrm{ml}^{-1}$ ), and were then tested for the presence of $\mathrm{pJM} 1$ by screening on M9 minimal medium plates containing the iron chelator ethylenediamine di-(o-hydroxyphenylacetic acid) at a concentration of $10 \mu \mathrm{M}$ (Singer \& Early, 1989). Of the $17 \mathrm{Rif}^{\mathrm{A}} \mathrm{Ap}^{\mathrm{r}}$ exconjugants tested, only three still retained pJM1, as evidenced by growth in the presence of ethylenediamine di-(o-hydroxyphenylacetic acid). These strains were chosen for further study, and were grown in the absence of selection to permit segregation of unstable pBR322 plasmids. Ap ${ }^{s}$ clones were then re-tested as recipients in conjugal matings with HB101(pBR322) and HB101(pRK2013). One clone that appeared to act as an efficient recipient was designated $V$. anguillarum R1Rsut(pJM1) and was characterized further.

\section{Characterization of a restriction-defective mutant of $V$. anguillarum}

The results presented in Table 3 show that $V$. anguillarum R1Rsut(pJM1) was able to act as a conjugal recipient in triparental matings as efficiently as the pJM1-cured strain $V$. anguillarum H775-3. In addition, plasmid transfer frequencies with $V$. anguillarum R1Rsut(pJM1) recipients were similar regardless of whether the donor was E. coli $\mathrm{HB} 101$ or ER 1647. These results suggest that $V$. anguillarum R1Rsut(pJM1) is a restriction-defective mutant that arose as a result of UV mutagenesis. The putative mutagenic event did not result in the detectable deletion of pJM1 plasmid DNA, nor in its rearrangement, as plasmid fingerprints with EcoRI, HindIII, XhoI and PstI were still indistinguishable for pJMI DNA purified from $V$. anguillarum R1Rsut(pJM1) and from wild-type $V$. anguillarum $\mathrm{R} 1$ (pJM1).

If a mutation is responsible for the apparent restriction-defective phenotype of $V$. anguillarum R1Rsut(pJM1), then it should be possible to quantify differences in endonuclease activities between $V$. anguillarum R1Rsut(pJM1) and wild-type $V$. anguillarum 
Rl(pJM1). Each strain was tested for the presence of type II restriction endonucleases by the method of Schleif (1980), with uniformly negative results. This was unexpected, since some $V$. anguillarum strains were previously shown to produce VanI, an isoschizomer of BgII (Wood, 1988). Both strains did, however, produce unusually high levels of non-specific exonuclease activity that could easily have masked any specific type II activity. Because of this potential masking, putative restriction endonucleases were purified from 3-litre cultures of each strain and were fractionated as previously described using Phosphocellulose P11 (Whatman) and Hydroxylapatite $\mathrm{C}$ (Clarkson Chem. Co.) (Makula \& Meagher, 1980). Partial purification and fractionation revealed no type II restriction endonuclease activities in purified fractions from either of the above two strains. There was, however, a pronounced difference in the levels of nonspecific nuclease activity produced by each strain, with $V$. anguillarum R1Rsut(pJM1) producing only about $30-35 \%$ of the nuclease activity exhibited in fractions from $V$. anguillarum $\mathrm{R} 1$ (pJM1). V. anguillarum $\mathrm{H} 775-3$ produced levels of nuclease activity similar to those observed with $V$. anguillarum R1Rsut(pJM1) (Ronald A. Makula, personal communication).

Based on the above data, it is tempting to speculate that a UV-induced mutation has resulted in a decrease in a pJM1-mediated type I-like restriction activity in $V$. anguillarum R1 Rsut(pJM1). However, we have no direct genetic evidence linking relief from restriction with a specific mutation, or with the apparent decrease in observed nuclease activity. In addition to the possibility that $\mathrm{pJM} 1$ encodes a restriction-modification-like system, it is also possible that $\mathrm{pJMl}$ encodes a trans-acting factor that activates expression of a chromosomallyencoded restriction-modification system. However, we have been unable to demonstrate any restriction activity in $E$. coli transformants harbouring cloned pJM1 DNAs, or in $V$. anguillarum $\mathbf{H} 775-3$ exconjugants carrying cloned pJM1 DNA fragments.

Regardless of the restriction mechanism involved, other investigators have also been unsuccessful using $V$. anguillarum as a conjugal recipient in matings performed by a variety of techniques and with a variety of Gramnegative bacterial donors (Toranzo \& Barja, 1985). In addition, pJM1-like plasmids have only rarely been observed in the presence of other plasmids in natural isolates of V. anguillarum (Conchas et al., 1991; Crosa et al., 1977; Larsen \& Olsen, 1991 ; Myhr et al., 1991 ; Olsen \& Larsen, 1990; Tolmasky et al., 1988; Wiik et al., 1989), and previous to our earlier studies (Singer et al., $1991 a$, $b$ ), only broad-host-range plasmids related to RP4 were transferred to $V$. anguillarum $775(\mathrm{pJM} 1)$. It is possible that a pJM1-mediated restriction system is responsible for the above observations, and that such a system may limit the spread of plasmids to $V$. anguillarum under natural conditions. If this putative restriction system functions in the marine environment, it could be advantageous to aquaculturists in limiting the spread of $\mathrm{R}$-factors among populations of $\boldsymbol{V}$. anguillarum selected by antibiotic chemotherapy used to treat or prevent vibriosis.

This work was supported by funds from the University of Maine Agricultural Experiment Station and an NSF EPSCoR award. We thank Catherine A. Hopper for expert technical assistance.

This is publication no. 1663 of the Maine Agricultural Experiment Station.

\section{References}

Austin, B. \& Austin, A. (1987). Bacterial Fish Pathogens: Disease in Farmed and Wild Fish. Edited by B. Austin \& A. Austin. Chichester: Ellis Horwood.

Balbas, P., Soberon, X., Bolivar, F. \& Rodriguez, R. L. (1988). The plasmid, pBR322. In Vectors, pp. 5-41. Edited by R. L. Rodriguez \& D. T. Denhardt. Boston, MA: Butterworth.

Bolinches, J., Lemos, M. L., Fouz, B., Cambra, M., Larsen, J. L. \& Toranzo, A. E. (1990). Serological relationships among Vibrio anguillarum strains. Journal of Aquatic Animal Health 2, 21-29.

Conchas, R. F., Lemos, M. L., Barja, J. L. \& Toranzo, A. E. (1991). Distribution of plasmid- and chromosome-mediated iron uptake systems in Vibrio anguillarum strains of different origins. Applied and Environmental Microbiology 57, 2956-2962.

Crosa, J. H. (1989). Genetics and molecular biology of siderophoremediated iron transport in bacteria. Microbiological Reviews 53, 517 530.

Crosa, J. H., Schiewe, M. H. \& Falkow, S. (1977). Evidence for plasmid contribution to the virulence of the fish pathogen Vibrio anguillarum. Infection and Immunity 18, 509-513.

Crosa, J. H., Actis, L. A., Mitoma, Y., Perez-Casal, J., Tolmasky, M. E. \& Valvano, M. A. (1985). Plasmid mediated iron sequestering systems in pathogenic strains of Vibrio anguillarum and Escherichia coli. In Plasmids in Bacteria, pp. 759-774. Edited by D. R. Helinski, S. N. Cohen, D. B. Clewell, D. A. Jackson \& A. Hollaender. New York: Plenum Press.

Ditta, G., Stanfield, S., Corbin, D. \& Helinski, D. R. (1980). Broad host range DNA cloning system for Gram-negative bacteria: construction of a gene bank of Rhizobium meliloti. Proceedings of the National Academy of Sciences of the United States of America 77, 7347-7351.

FigURSKI, D. H. \& HelinsKi, D. R. (1979). Replication of an origincontaining derivative of plasmid RK2 dependent on a plasmid function provided in trans. Proceedings of the National Academy of Sciences of the United States of America 76, 1648-1652.

LARSEN, J. L. \& OlsEN, J. E. (1991). Occurrence of plasmids in Danish isolates of Vibrio anguillarum serovars $\mathrm{O} 1$ and $\mathrm{O} 2$ and association of plasmids with phenotypic characteristics. Applied and Environmental Microbiology 57, 2158-2163.

Larsen, J. L., Rasmussen, H. B. \& DalsgaArd, I. (1988). Study of Vibrio anguillarum strains from different sources with emphasis on ecological and pathobiological properties. Applied and Environmental Microbiology 54, 2264-2267.

Lemos, M. L., Salinas, P., Toranzo, A. E., Barja, J. L. \& Crosa, J. H. (1988). Chromosome-mediated iron uptake system in pathogenic strains of Vibrio anguillarum. Journal of Bacteriology 170, 1920-1925.

Lizardi, P. M., Binder, R. \& ShORT, S. A. (1984). Preparative isolation of DNA and biologically active mRNA from DEAE membrane. Gene Analytical Technology 1, 22-28. 
Makula, R. A. \& Meagher, R. B. (1980). A new restriction endonuclease from the anaerobic bacterium, Desulfovibrio desulfuricans, Norway. Nucleic Acids Research 8, 3125-3131.

Myhr, E., Larsen, J. L., Lillehaug, A., Gudding, R., Heum, M. \& HASTEIN, T. (1991). Characterization of Vibrio anguillarum and closely related species isolated from farmed fish in Norway. Applied and Environmental Microbiology 57, 2750-2757.

Olsen, J. E., \& LaRSEN, J. L. (1990). Restriction fragment length polymorphism of the Vibrio anguillarum serovar $\mathrm{O} 1$ virulence plasmid. Applied and Environmental Microbiology 56, 3130-3132.

RALeigh, E. A. \& WiLson, G. (1986). Escherichia coli K-12 restricts DNA containing 5-methyl cytosine. Proceedings of the National Academy of Sciences of the United States of America 83, 9070-9074.

Raleigh, E. A., Benner, J., Bloom, F., Bramer, H. D., DeCruz, E., Dharmalingam, K., Heitman, J., Noyer-Weidner, M., PieKAROWICZ, A., KRETZ, P. L., Short, J. M., \& WOODCOCK, D. (1991). Nomenclature relating to restriction of modified DNA in Escherichia coli. Journal of Bacteriology 173, 2707-2709.

SCHLEIF, R. (1980). Assaying of organisms for the presence of restriction endonucleases. Methods in Enzymology 65, 19-23.

Singer, J. T. \& EarleY, S. (1989). Identification of polypeptides encoded by cloned pJM1 iron uptake DNA isolated from Vibrio anguillarum 775. Journal of Bacteriology 5, 2293-2302.

Singer, J. T., CHOE, W. \& SCHMIDT, K. A. (1991 a). Use of a restrictiondefective variant for the construction of stable attenuated strains of the marine fish pathogen Vibrio anguillarum. Journal of Microbiological Methods 13, 49-60.

Singer, J. T., Schmidt, K. A. \& Reno, P. W. (1991 b). Polypeptides p40, pOM2, and pAngR are required for iron uptake and for virulence of the marine fish pathogen Vibrio anguillarum 775. Journal of Bacteriology 173, 1347-1352.
Threlfall, E. J., Rowe, B. \& Ward, L. R. (1989). Subdivision of Salmonella enteritidis phage types by plasmid profile typing. Epidemiology and Infection 102, 459-465.

Thomas, C. M. (1981). Molecular genetics of broad host range plasmid RK2. Plasmid 5, 10-19.

Tolmasky, M. E., Salinas, P. C., Actis, L. A. \& Crosa, J. H. (1988). Increased production of the siderophore anguibactin mediated by pJM1-like plasmids in Vibrio anguillarum. Infection and Immunity 56 $1608-1614$.

Toranzo, A. E. \& BARJA, J. L. (1985). Effect of experimental procedures on the determination of drug resistance transfer in bacterial fish pathogens. Bulletin of the European Association of Fish Pathology 5, 51-54

TORANZO, A. E. \& BARJA, J. L. (1990). A review of the taxonomy and seroepidemiology of Vibrio anguillarum with special reference to the aquaculture in northwest of Spain. Diseases of Aquatic Organisms 9 , 73-82.

Toranzo, A. E., SANtos, Y., Lemos, M. L., Ledo, A. \& Bolinches, J. (1987). Homology of Vibrio anguillarum strains causing epizootics in turbot, salmon, and trout reared on the Atlantic coast of Spain. Aquaculture 67, 41-52.

VieirA, J. \& Messing, J. (1982). The pUC plasmids, an M13mp7derived system for insertion mutagenesis and sequencing with synthetic universal primers. Gene 19, 259-268.

WiIK, R., HofF, K. A., ANDersen, K. \& DAAe, F. L. (1989) Relationships between plasmids and phenotypes of presumptive strains of Vibrio anguillarum isolated from different fish species. Applied and Environmental Microbiology 55, 826-831.

WooD, P. (1988). Appendix. In New England Biolabs 1988-1989 Catalog, p. 87. Beverly, Massachusetts: New England Biolabs. 